\title{
Conference Paper \\ Polylactic Acid (PLA) Composite Films Reinforced with Wet Milled Jute Nanofibers
}

\author{
Vijay Baheti, Jiri Militky, and S. Z. Ul Hassan \\ Department of Material Engineering, Technical University of Liberec, Liberec, Czech Republic \\ Correspondence should be addressed to Vijay Baheti; vijaykumar.baheti@gmail.com
}

Received 1 August 2013; Accepted 8 September 2013

Academic Editors: R. Fangueiro and H. Hong

This Conference Paper is based on a presentation given by S. Z. Ul Hassan at "International Conference on Natural FibersSustainable Materials for Advanced Applications 2013” held from 9 June 2013 to 11 June 2013 in Guimarães, Portugal.

Copyright (C 2013 Vijay Baheti et al. This is an open access article distributed under the Creative Commons Attribution License, which permits unrestricted use, distribution, and reproduction in any medium, provided the original work is properly cited.

\begin{abstract}
In the present study, waste jute fibers formed in textile industries were wet pulverized to nanoscale using high energy planetary ball milling. The rate of refinement of uncleaned jute fibers having noncellulosic contents was found slower than the cleaned jute fibers. This behavior is attributed to the strong holding of fiber bundles by noncellulosic contents which offered resistance to the defibrillation during wet milling. In addition, the pulverization of fibers in the presence of water prevents the increase in temperature of mill which subsequently avoided the sticking of material on the milling container. After three hours milling, the diameter of nanofibers was observed around $50 \mathrm{~nm}$. In the further stage, obtained nanofibers were incorporated under $1 \mathrm{wt} \%, 5 \mathrm{wt} \%$, and $10 \mathrm{wt} \%$ loading into polylactic acid composite films. The potentials of jute nanofibers were investigated for improvement in mechanical and barrier properties of films. The maximum improvement in mechanical properties was observed in case of $5 \mathrm{wt} \%$ composite film where Young's modulus was increased to $3.3 \mathrm{GPa}$ from $1.0 \mathrm{GPa}$ as compared with neat PLA film.
\end{abstract}

\section{Introduction}

The demand for textiles has increased significantly in the last decade due to the rise in the living standards of people. However, increased demands of textiles also brought the challenges to dispose significant amount of wastes, generated during the processing and end of life textile materials $[1,2]$. In recent years, research on recycling and reuse of textile wastes, instead of landfilling or incineration, has gained a lot of importance due to the increased awareness of environmental concerns. Traditionally, textile wastes have been converted to individual fiber stage through cutting, shredding, carding, and other mechanical processes. The fibers are then rearranged into products for applications in garment linings, household items, furniture upholstery, automotive carpeting, automobile sound absorption materials, carpet underlays, building materials for insulation and roofing felt, and lowend blankets $[1,2]$. However, recent increased competition and reduced profit margins of such industries have forced the researchers to find alternative more profitable applications of textile wastes. One such interesting way is to separate the nanofibrils or nanocrystals from the textile wastes and subsequently incorporate them into high performance functional products.

The lists of the previous literature articles have reported the remarkable mechanical properties of cellulose nanofibers in the range of $130-160 \mathrm{GPa}$ that resulted from parallel arrangement of molecular chains without folding [3-5]. As a result, cellulose nanofibers have been used in value added applications such as reinforced biodegradable nanocomposites, foams, aerogels, optically transparent functional materials, and oxygen-barrier layers [6-8].

The noncellulosic substances in waste jute fibers (i.e., lignin, hemicelluloses, and waxy materials) hinder the reaction between hydroxyl groups of fibers and polymer matrices and consequently deteriorate the mechanical properties of composites [9-11]. In order to have better bonding between fibers and matrix, the noncellulosic contents must be removed from the waste jute fibers. In the present study, pretreatment of waste jute fibers with a sequential 
action of alkali and bleaching was carried out, due to its inexpensive nature $[12,13]$, for the removal of lignin and hemicelluloses. In the subsequent stage, cleaned waste jute fibers were subjected to wet pulverization in high energy planetary ball milling process to separate jute nanofibers. During the process of ball milling, fibers tend to defibrillate under the shearing action of frictional force of balls and subsequently refine to nanosegments due to the impact force $[7,8]$. In fact, ball milling technique has been found to be simple, economical, and ecofriendly, over commonly preferred strong acid hydrolysis used for the separation of cellulose nanocrystals.

The present paper deals with the wet pulverization of waste jute fibers to nanoscale using high energy planetary ball milling process. The prepared nanofibers were then incorporated into polylactic acid to improve their mechanical, thermal, and barrier properties. The biodegradable nanocomposite films can be expected to serve in food packaging films, agriculture mulch cover, and so forth.

\section{Experimental}

2.1. Materials. Short waste jute fibers were obtained from India. The fibers were measured to have a density of $1.58 \mathrm{~g} /$ $\mathrm{cm}^{3}$, modulus of $20 \mathrm{GPa}$, tensile strength of $440 \mathrm{MPa}$, and elongation of $2 \%$. Polylactic acid (PLA) was purchased from NatureWorks LLC, USA, through local supplier Res-inex, Czech Republic. The PLA had a density of $1.25 \mathrm{~g} / \mathrm{cm}^{3}$ and the average molecular weight (Mw) of 200,000. Chloroform which was used as solvent was purchased from Thermo Fisher, Czech Republic.

2.2. Pulverization of Jute Fibers to Nanofibers. In the beginning, chemical pretreatment of jute fibers was carried out sequentially with $4 \mathrm{wt} \%$ sodium hydroxide $(\mathrm{NaOH})$ at $80^{\circ} \mathrm{C}$ for 1 hour and with $7 \mathrm{~g} / \mathrm{L}$ sodium hypochlorite $(\mathrm{NaOCl})$ at room temperature for 2 hours under $\mathrm{pH}$ 10-11. Subsequently, the fibers were antichlor treated with $0.1 \%$ sodium sulphite $\left(\mathrm{Na}_{2} \mathrm{SO}_{3}\right)$ at $50^{\circ} \mathrm{C}$ for $20 \mathrm{~min}$ [7].

High energy planetary ball milling (Fritsch pulverisette 7, Germany) was used for wet pulverization of waste jute fibers in distilled water. The sintered corundum container of $80 \mathrm{~mL}$ capacity and zirconium balls of $3 \mathrm{~mm}$ diameter were chosen for 3 hours of wet milling. The ball to material ratio (BMR) was kept at $10: 1$, and the speed was kept at $850 \mathrm{rpm}$ with reverse rotation of containers. At the end of wet milling, jute particles were separated from water by centrifugation at $4000 \mathrm{rpm}$ and simultaneously transferred to isopropanol to avoid hornification during drying [7].

Particle size distribution of wet milled jute particles was studied after each hour of milling on a dynamic light scattering instrument (Malvern zetasizer nanoseries). Deionized water was used as a dispersion medium, and it was ultrasonicated for $5 \mathrm{~min}$ with bandelin ultrasonic probe before particle size measurement. Refractive index of 1.52 for water was used to calculate particle size of wet milled jute fibers.

In addition, morphologies of wet milled jute particles were observed on scanning electron microscope (SEM) of
TS5130-Tescan at $30 \mathrm{KV}$ accelerated voltage and on field emission scanning electron microscope (FESEM) of Zeiss at $5 \mathrm{kV}$ accelerated voltage. The amount of $0.01 \mathrm{~g}$ of jute particles was dispersed in $100 \mathrm{~mL}$ acetone, and then a drop of the dispersed solution was placed on aluminum foil and gold coated after drying.

\subsection{Preparation of Nanocomposite Thick Films. PLA/jute} nanofiber composite films with 1, 5, and $10 \mathrm{wt} \%$ filler content were prepared by mixing the calculated amount of jute nanofibers with 5\% PLA in chloroform using a magnetic stirrer. The stirring was performed at room temperature for 3 hours. The composite mixture was further ultrasonicated for 10 min on Bandelin Ultrasonic probe mixer with 50-horn power. The final mixtures were then cast on a Teflon sheet in order to prevent sticking of the nanocomposite film. The films were kept at room temperature for 2 days until they were completely dried and then removed from the Teflon sheet. Neat PLA film was also prepared as a reference control sample for comparison purpose.

\subsection{Characterization}

2.4.1. Differential Scanning Calorimetry (DSC). The melting and crystallization behaviors of the neat and composite films were investigated on DSC 6 Perkin Elmer instrument using Pyris software under nitrogen atmosphere with sample weight of $7 \mathrm{mg}$. The sample was heated from $25^{\circ} \mathrm{C}$ to $200^{\circ} \mathrm{C}$ at a rate of $5^{\circ} \mathrm{C} / \mathrm{min}$. The crystallinity (\%) of the PLA was estimated from the following equation:

$$
\% \text { Crystallinity }=\left(\frac{\Delta H_{f}}{w \times \Delta H_{0}}\right) \times 100 \% \text {, }
$$

where $\Delta H_{f}$ is heat of melting of sample, $\Delta H_{0}$ is heat of melting $100 \%$ crystalline PLA $93 \mathrm{j} / \mathrm{g}$ [8], and $w$ is mass fraction of PLA in nanocomposite.

2.4.2. Tensile Properties. Tensile testing was carried out using a miniature material tester Rheometric Scientific MiniMat 2000 with a $1000 \mathrm{~N}$ load cell at a crosshead speed of $10 \mathrm{~mm} /$ min. The samples were prepared by cutting strips from the films with a width of $10 \mathrm{~mm}$. The length between the grips was kept $100 \mathrm{~mm}$. Ten samples were measured for each sample. Further, the morphology of nanocomposite films was investigated using scanning electron microscope TS5130Tescan SEM at $20 \mathrm{KV}$ accelerated voltage.

2.4.3. Oxygen Barrier Properties. Oxygen barrier property $\left(\mathrm{mL} / \mathrm{m}^{2} \cdot 24 \mathrm{~h} \cdot 0.1 \mathrm{MPa}\right)$ of $10 \mathrm{~cm}$ circular sample was measured by manometric method using permeameter Lyssy L100-5000 on Systech Instrument, USA at $23^{\circ} \mathrm{C}$ and $0 \% \mathrm{RH}$, respectively.

2.4.4. Water Vapour Barrier. Water vapour barrier property $\left(\mathrm{g} / \mathrm{m}^{2} \cdot \mathrm{d}\right)$ of $6.5 \mathrm{~cm}$ circular sample was measured using the gravimetric method $\mathrm{ZM}-23$ at $38^{\circ} \mathrm{C}$ and $85 \% \mathrm{RH}$, respectively. 


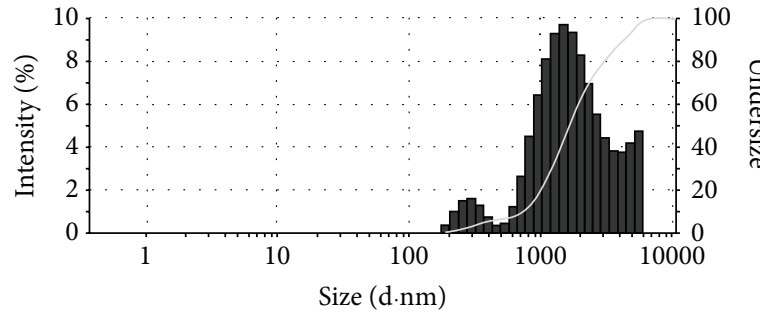

(a)

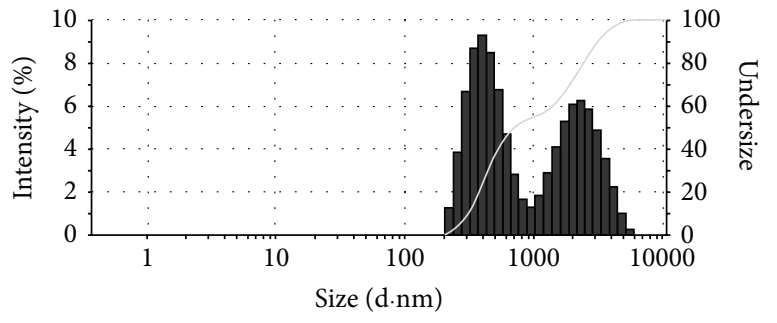

(b)

Figure 1: (a) Particle size distribution of one hour dry milling. (b) Particle size distribution of one hour wet milling.

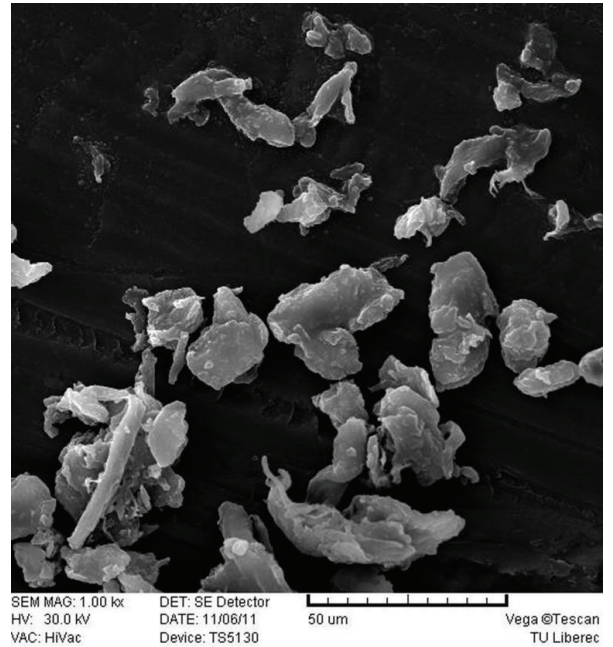

(a)

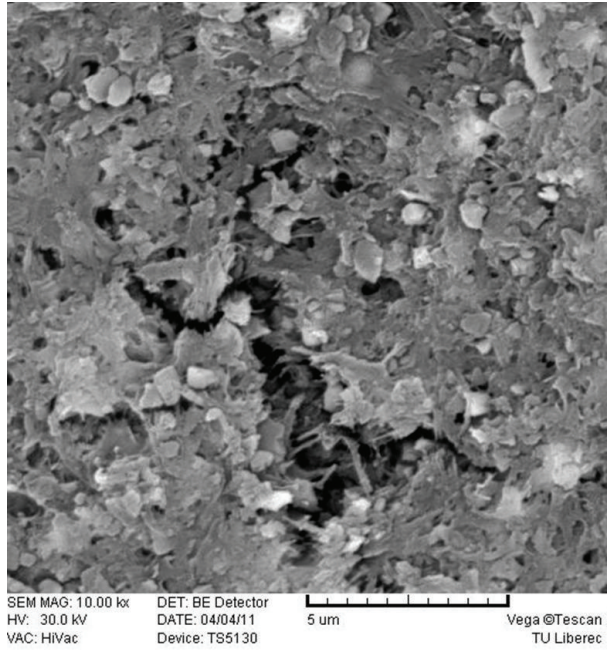

(b)

FIGURE 2: (a) SEM image of one hour dry milling. (b) SEM image of one hour wet milling.

\section{Results and Conclusions}

3.1. Effect of Milling Condition on Particle Size Reduction of Jute Fibers. Under one hour of dry milling, jute fibers were pulverized to microparticles with an average size of $1480 \mathrm{~nm}$ in wider particle size distribution as shown in Figures 1(a) and 2(a). The multimodal distribution of particles is attributed to the increase in temperature within the mill because of continuous impact of balls [7]. The increase in temperature of mill resulted in the deposition of jute particles on the surface of milling container and balls. In case of wet milling, the increase in temperature was slowed down by deionised water which consequently resulted in narrow particle size distribution with an average particle size of $\sim 640 \mathrm{~nm}$ after one hour of wet milling as shown in Figures 1(b) and 2(b). In other words, uniformity in impact action of balls on every individual particle can be guaranteed during milling in wet condition [7].

\subsection{Effect of Wet Milling Time on Particle Size Reduction} of Jute Fibers. When waste jute fibers were subjected to extended duration of wet milling, the average particle size reached to $443 \mathrm{~nm}$ after 3 hours of wet milling, and the particle size distribution changes slowly from multimodal nature to unimodal nature as shown in Figure 3(a). This showed the consistency and homogeneity in milling action on every individual particle as milling continued for longer time. However, the surface of milling balls which are of expensive materials also started to get deteriorated with the increase in the wet milling time [7].

The shape of jute particles was observed in the form of nanofibers having diameter around $50 \mathrm{~nm}$ as shown in Figure 3(b). It was also possible to see few particles without aspect ratio which might be considered as agglomerates of hundreds of individual jute nanofibers.

3.3. Thermal Behavior of Nanocomposite Films. Table 1 shows that $T_{g}$ and $T_{m}$ values of PLA increased with the increased loading of jute nanofibers. The maximum improvement was observed in case of $10 \mathrm{wt} \%$ of jute nanofibers where $T_{g}$ was increased from $42^{\circ} \mathrm{C}$ to $49^{\circ} \mathrm{C}$, and $T_{m}$ was increased from $147^{\circ} \mathrm{C}$ to $153^{\circ} \mathrm{C}$ as compared to the neat PLA film. The higher values of $T_{g}$ are attributed to the delay in polymer relaxation due to the restriction in chain mobility caused by the presence of nanofibers. On the other hand, the increased value of $T_{m}$ can be attributed to the formation of bigger crystals. The wider peak of crystallization temperature for nanocomposite films shown in Figure 4 indicated an enhanced crystallization 


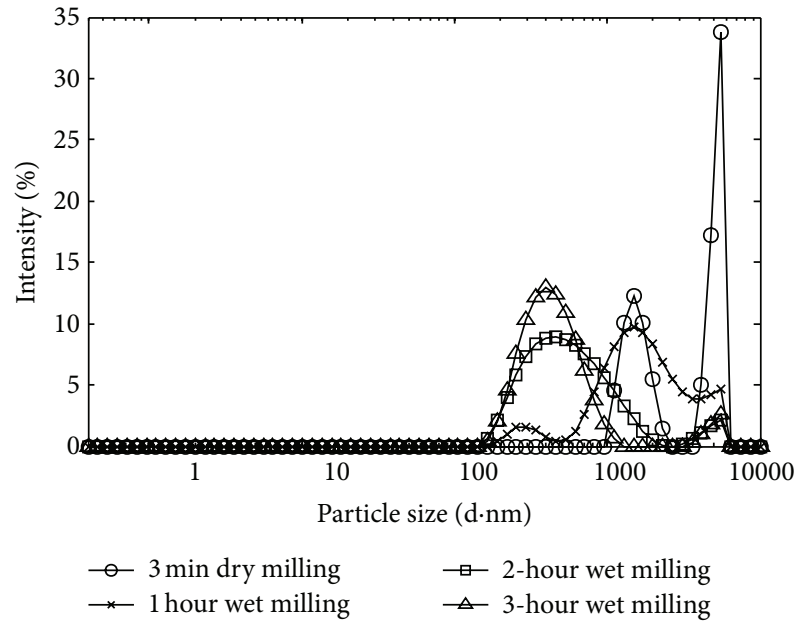

(a)

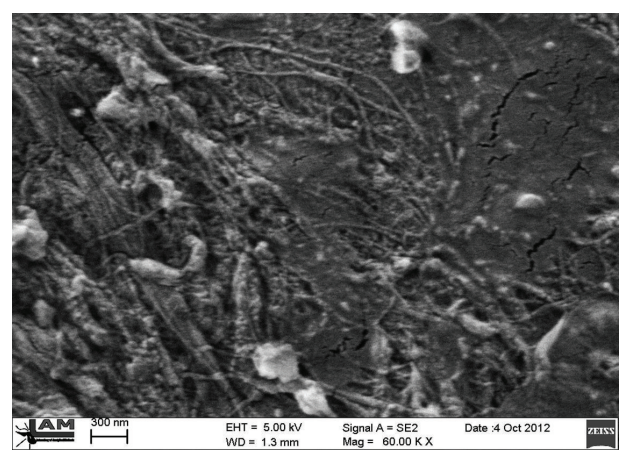

(b)

FIgURE 3: (a) Effect of extended wet milling time on pulverization. (b) FESEM image of particle size after 3-hour wet milling.

TABLE 1: Behavior of PLA/JNF composite films on application of heat.

\begin{tabular}{|c|c|c|c|c|c|}
\hline Sample & $T_{g}\left({ }^{\circ} \mathrm{C}\right)$ & $T_{c}\left({ }^{\circ} \mathrm{C}\right)$ & $T_{m}\left({ }^{\circ} \mathrm{C}\right)$ & $\Delta H(\mathrm{~J} / \mathrm{g})$ & Crystallinity \% \\
\hline Neat PLA & 42.35 & 98.85 & 147.49 & 17.33 & 18.63 \\
\hline $1 \% \mathrm{JNF}+\mathrm{PLA}$ & 42.84 & 97.90 & 153.15 & 20.52 & 22.28 \\
\hline $5 \% \mathrm{JNF}+\mathrm{PLA}$ & 46.01 & 97.70 & 153.14 & 24.74 & 26.84 \\
\hline $10 \%$ JNF + PLA & 49.00 & 96.43 & 153.97 & 26.38 & 30.21 \\
\hline
\end{tabular}
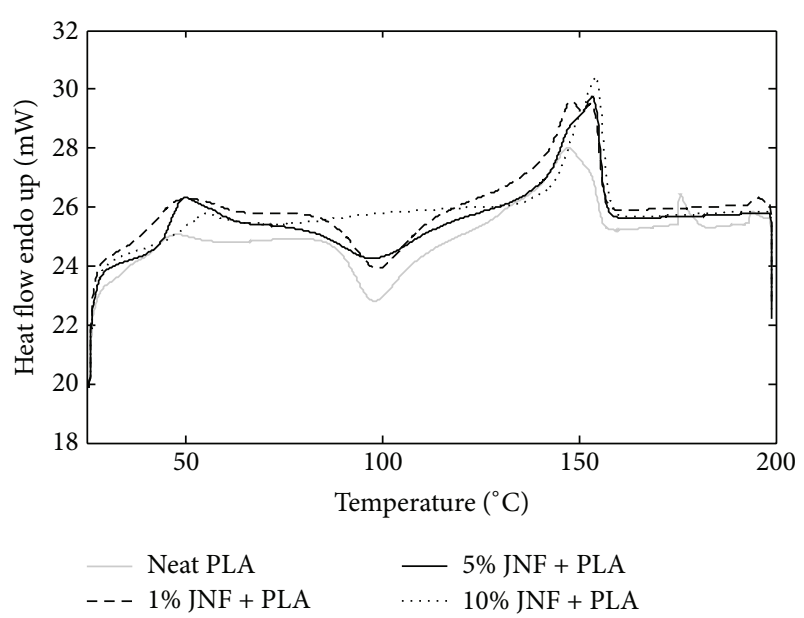

FIGURE 4: DSC of neat PLA and nanocomposite films.

rate of PLA molecules in the presence of jute nanofibers due to their nucleating ability. The increase in crystallinity of PLA after addition of jute nanofibers was confirmed from the increase in heat of melting values given in Table 1.

3.4. Mechanical Properties of Nanocomposite Films. Figure 5 shows that the modulus of the PLA films increased significantly from $1.04 \mathrm{GPa}$ to $3.3 \mathrm{GPa}$ with the addition of $5 \mathrm{wt} \%$ jute nanofibers. The improved interaction between nanofibers and matrix, together with higher crystallinity

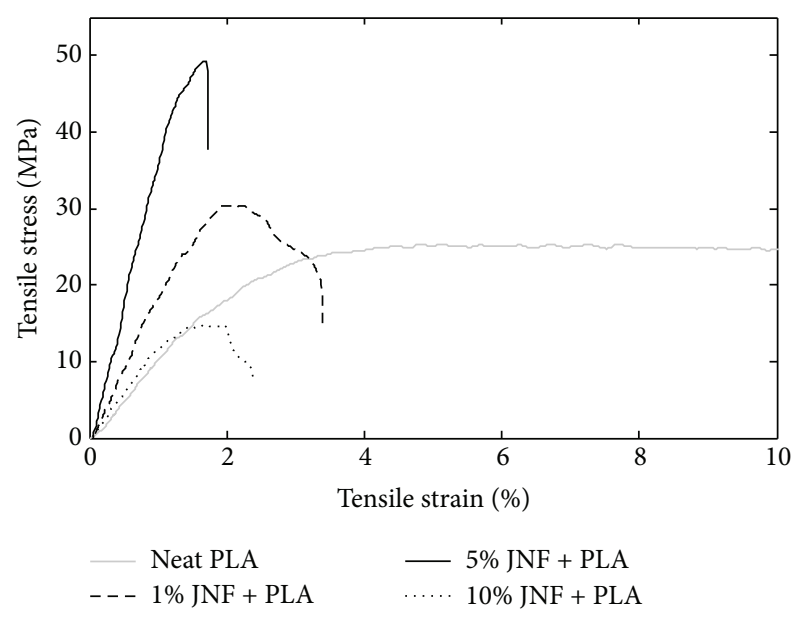

FIGURE 5: Stress-strain curve of neat PLA and nanocomposite films.

of PLA in composites, can be attributed to the increase in modulus of the composites as compared to neat PLA. In order to understand the interaction between PLA and jute nanofibers, the morphology of fractured surfaces were studied under the SEM as shown in Figure 6. The fractured surface of $5 \mathrm{wt} \%$ nanocomposites (Figure 6(c)) shows the presence of wrinkles in contrast to the smooth surface of $1 \mathrm{wt} \%$ nanocomposite (Figure 6(b)). The wrinkles and roughness on the surface indicated greater stress transfer from matrix to jute nanofibers and consequent improvement in the 


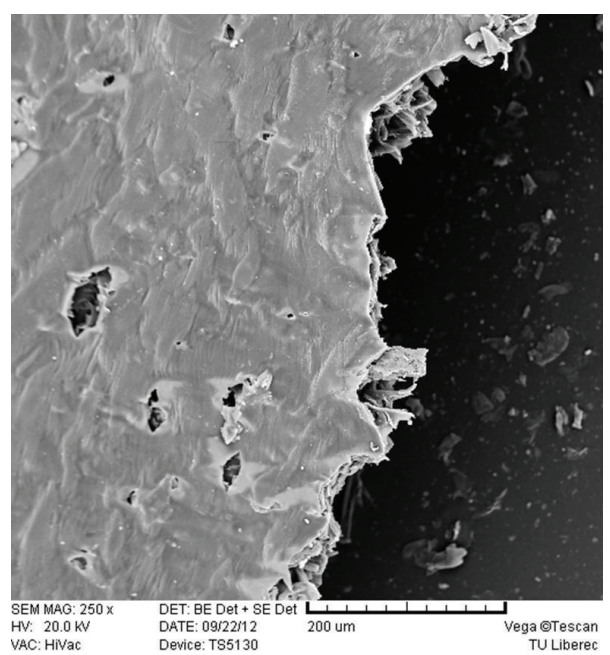

(a)

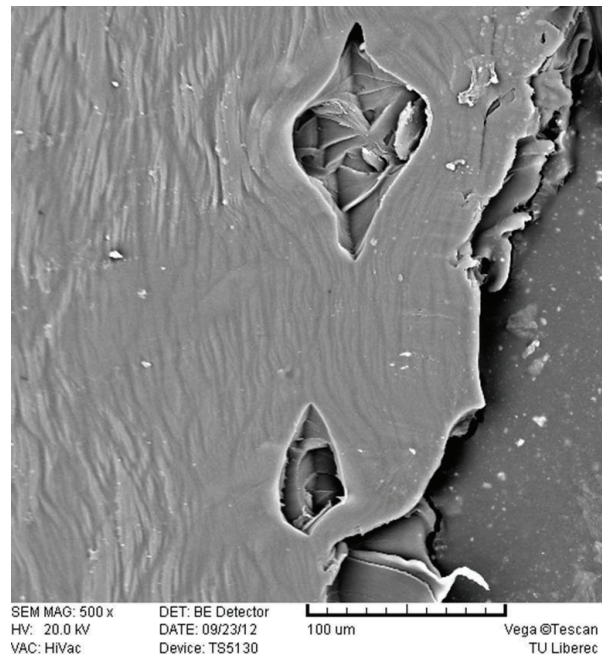

(c)

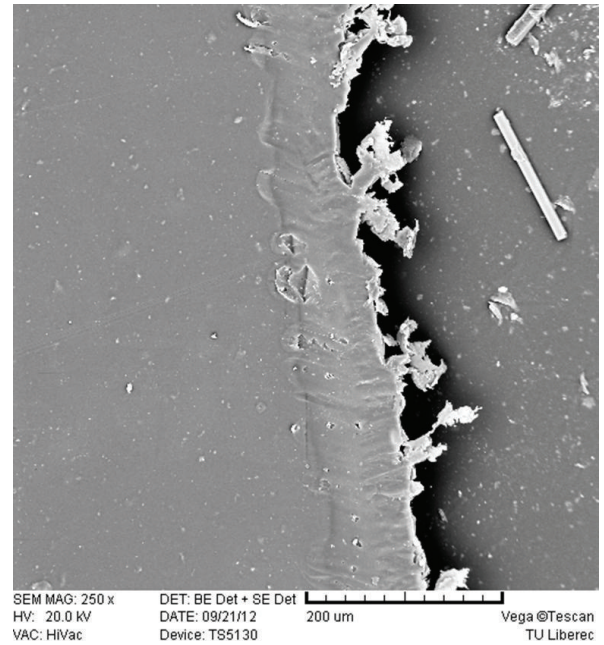

(b)

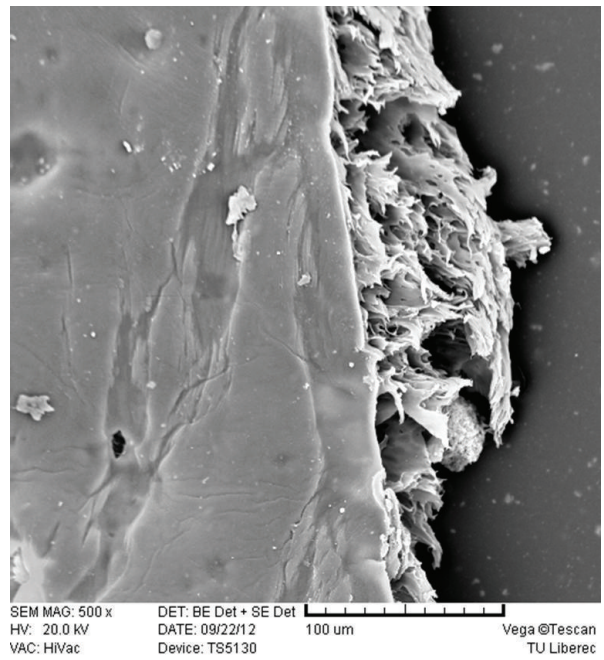

(d)

Figure 6: (a) Neat PLA film. (b) 1\% JNF/PLA film. (c) 5\% JNF/PLA film. (d) 10\% JNF/PLA film.

modulus of $5 \mathrm{wt} \%$ nanocomposite. Similarly, less number of voids around filler and matrix explained very good interfacial adhesion between them. With further increase in the loading of jute nanofibers to $10 \mathrm{wt} \%$, the modulus of composite films dropped significantly to $1.0 \mathrm{GPa}$. This could be explained by the clustering of nanofibers at higher loading, which results in the formation of voids at the interface of filler-matrix as shown in Figure 6(d).

\subsection{Barrier Properties of PLA/JNF Composite Film. Previous} studies reported that improvement in barrier properties is directly related to the tortuosities created by nanoparticles. The tortuous nature of path depends on the shape and aspect ratio of the filler, degree of exfoliation or dispersion, filler loading and orientation, adhesion to the matrix, moisture activity, filler-induced crystallinity, polymer chain immobilization, filler-induced solvent retention, degree of purity, porosity, and size of the permeate $[9,11]$.

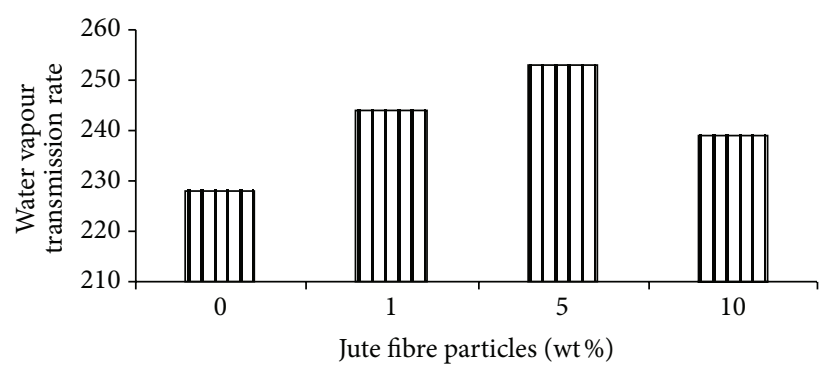

FIGURE 7: Moisture barrier of neat PLA and nanocomposite film.

PLA films after addition of jute nanofibers showed poor performance in water vapor and gas barrier behaviors at lower loading. Permeation rate of water vapor was found to increase in composite PLA films loaded with $1 \mathrm{wt} \%$ and $5 \mathrm{wt} \%$ jute nanofibers, and maximum permeation was observed in $5 \mathrm{wt} \%$ loading as shown in Figure 7. Similarly, the permeation 


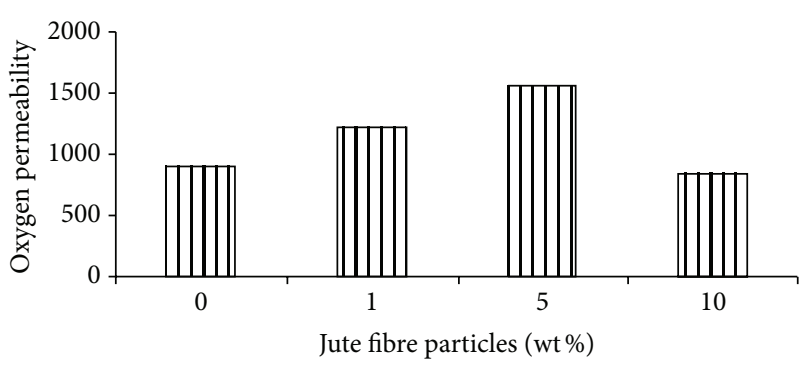

FIGURE 8: Oxygen barrier of neat PLA and nanocomposite film.

rate of oxygen was also observed higher in $1 \mathrm{wt} \%$ and $5 \mathrm{wt} \%$ composite films than neat PLA films from Figure 8. The main reasons behind poor barrier properties at lower loading can be related to the least improvement in crystallinity of matrix. In this way, the improvement in barrier performance at higher filler loading (i.e., $10 \mathrm{wt} \%$ ) is attributed to the maximum improvement in crystallinity of matrix.

\section{Conclusion}

The pulverization of jute fibers by high energy wet milling process is a simple, economical, and environment friendly approach for separation of nanofibers. The diameter of nanofibers reached $50 \mathrm{~nm}$ after 3 hours of wet milling. This technique has a very good scope on industrial scale for the refinement of large amount of waste fibers generated in the textile industry. When jute nanofibers were incorporated into PLA matrix for preparation of biodegradable nanocomposite films, the maximum improvements in mechanical properties were observed at $5 \mathrm{wt} \%$ loading of nanofibers. The improvements in properties are attributed to the increased interaction of nanofibers along with increased crystallinity of PLA. However, the deterioration in properties at $10 \mathrm{wt} \%$ loading of jute nanofibers is attributed to the nonhomogeneous stress transfer from matrix to fillers due to poor dispersion and agglomerations of nanofibers at higher filler loading. Further, the poor barrier performance of PLA films at lower loading of nanofibers is related with the least improvement of crystallinity of matrix.

\section{Acknowledgment}

The present study was supported by SGS Project number 48011 at the Technical University of Liberec, Czech Republic.

\section{References}

[1] W. Wang, Recycling in Textiles, Woodhead Publishing, Cambridge, UK, 2006.

[2] R. Horrocks, Recycling Textile and Plastic Waste, Woodhead Publishing, Cambridge, UK, 1996.

[3] T. Zimmermann, N. Bordeanu, and E. Strub, "Properties of nanofibrillated cellulose from different raw materials and its reinforcement potential," Carbohydrate Polymers, vol. 79, no. 4, pp. 1086-1093, 2010.
[4] H. Wang, L. Huang, and Y. Lu, "Preparation and characterization of micro- and nano-fibrils from jute," Fibers and Polymers, vol. 10, no. 4, pp. 442-445, 2009.

[5] V. Baheti, R. Abbasi, and J. Militky, "Ball milling of jute fibres wastes to prepare nanocellulose," World Journal of Engineering, vol. 9, no. 1, pp. 45-50, 2012.

[6] J. K. Pandey, W. S. Chu, C. S. Kim, C. S. Lee, and S. H. Ahn, "Bionano reinforcement of environmentally degradable polymer matrix by cellulose whiskers from grass," Composites B, vol. 40, no. 7, pp. 676-680, 2009.

[7] V. Baheti and J. Militky, "Reinforcement of wet milled jute nano/micro particles in polyvinyl alcohol films," Fibers and Polymers, vol. 14, no. 1, pp. 133-137, 2013.

[8] V. Baheti, R. Abbasi, J. Militky, and J. Dobias, "Barrier properties of poly lactic acid packaging films reinforced with jute micro/nano particles," Vlakna a Textil, vol. 19, no. 3, pp. 10-16, 2012.

[9] M. D. Sanchez-Garcia, E. Gimenez, and J. M. Lagaron, "Morphology and barrier properties of solvent cast composites of thermoplastic biopolymers and purified cellulose fibers," Carbohydrate Polymers, vol. 71, no. 2, pp. 235-244, 2008.

[10] T. Yu, J. Ren, S. Li, H. Yuan, and Y. Li, "Effect of fiber surface-treatments on the properties of poly(lactic acid)/ramie composites," Composites A, vol. 41, no. 4, pp. 499-505, 2010.

[11] G. Rodionova, M. Lenes, O. Eriksen, and O. Gregersen, "Surface chemical modification of microfibrillated cellulose: improvement of barrier properties for packaging applications," Cellulose, vol. 18, no. 1, pp. 127-134, 2011.

[12] M. S. Islam, K. L. Pickering, and N. J. Foreman, "Influence of alkali treatment on the interfacial and physico-mechanical properties of industrial hemp fibre reinforced polylactic acid composites," Composites A, vol. 41, no. 5, pp. 596-603, 2010.

[13] T. H. Nam, S. Ogihara, N. H. Tung, and S. Kobayashi, "Effect of alkali treatment on interfacial and mechanical properties of coir fiber reinforced poly(butylene succinate) biodegradable composites," Composites B, vol. 42, no. 6, pp. 1648-1656, 2011. 


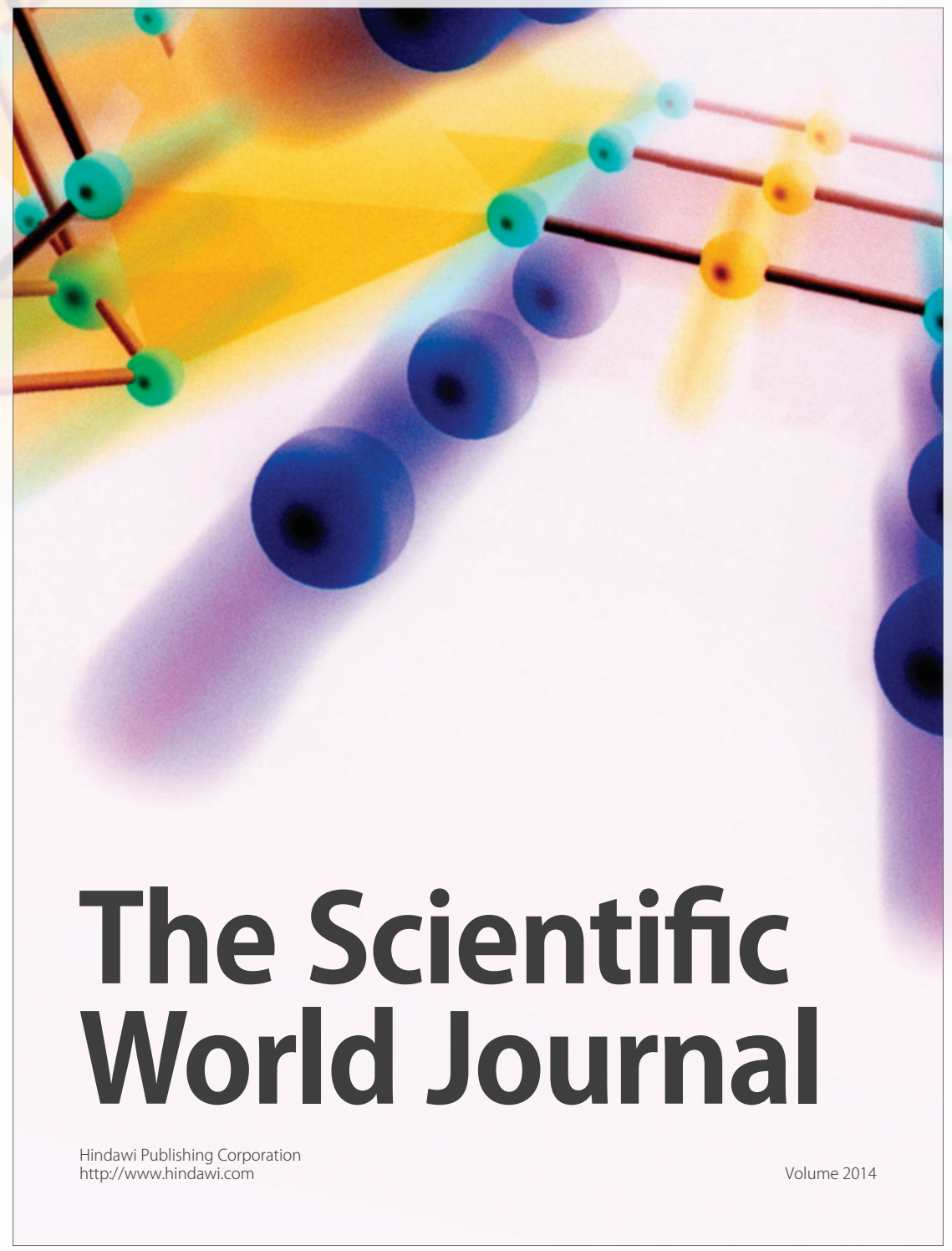

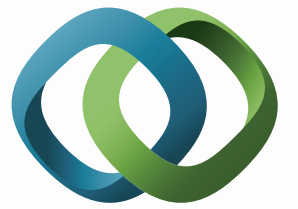

Hindawi
- Impact Factor $\mathbf{1 . 7 3 0}$

- 28 Days Fast Track Peer Review

- All Subject Areas of Science

- Submit at http://www.tswj.com 

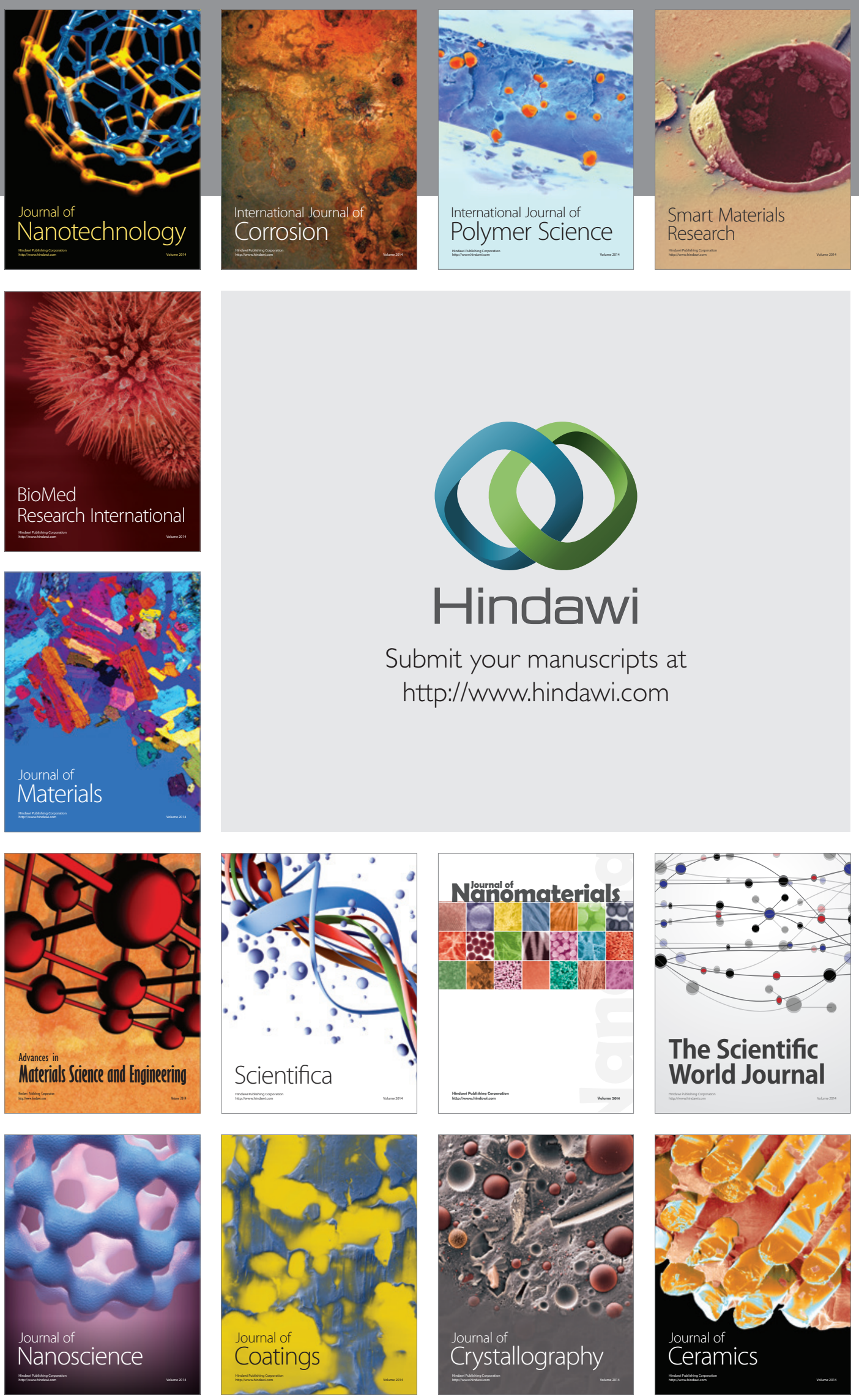

The Scientific World Journal

Submit your manuscripts at

http://www.hindawi.com

\section{World Journal}

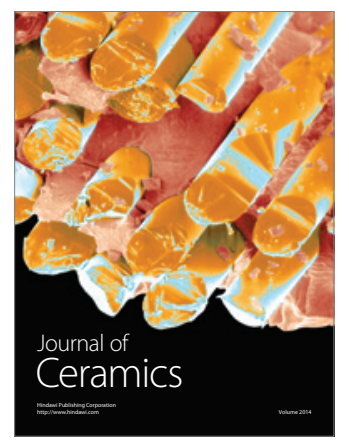

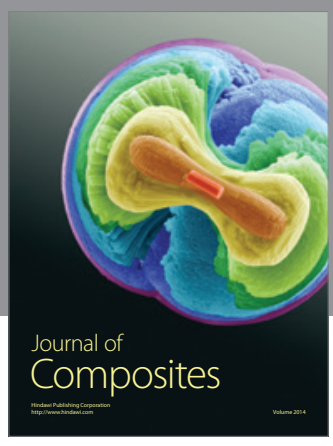
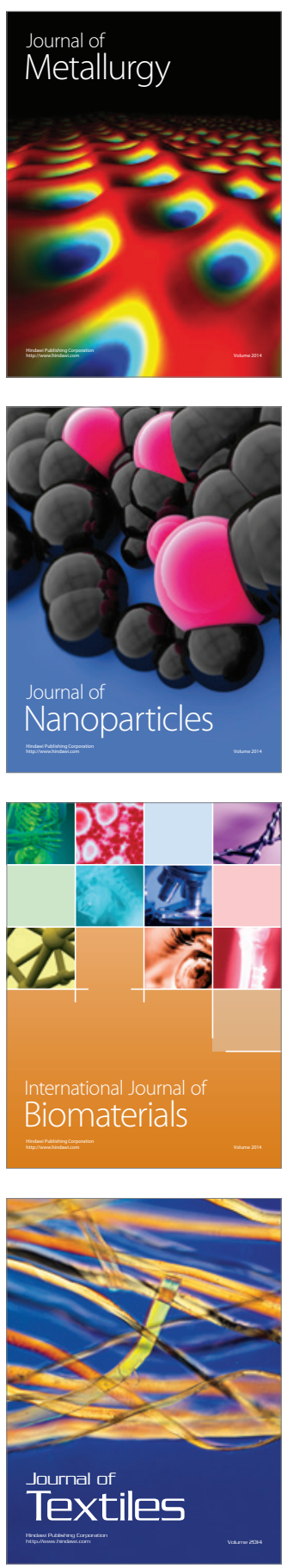